\title{
Publisher Correction: Microbial community-level regulation explains soil carbon responses to long- term litter manipulations
}

\author{
Katerina Georgiou (10 1,2, Rose Z. Abramoff (1) 2, John Harte ${ }^{3}$, William J. Riley ${ }^{2}$ \& Margaret S. Torn (iD) ${ }^{2,3}$
}

Nature Communications 8:1223 https://doi.org/10.1038/s41467-017-01116-Z; published online: 31 October 2017

The original PDF version of this Article contained an error in Table 1. On the right-hand side of the third row, the third equation was missing a $\beta$ as an exponent on the first $C_{\mathrm{B}}$, and incorrectly read:

$$
k_{\mathrm{B}} C_{\mathrm{B}}+r_{\mathrm{p}} C_{\mathrm{B}}=\frac{\varepsilon \cdot \mathrm{I}}{(1-\varepsilon)}
$$

The correct form of the equation is as follows:

$$
k_{\mathrm{B}} C_{\mathrm{B}}{ }^{\beta}+r_{\mathrm{p}} C_{\mathrm{B}}=\frac{\varepsilon \cdot \mathrm{I}}{(1-\varepsilon)}
$$

This has now been corrected in the PDF version of the Article. The HTML version was correct from the time of publication.

Published online: 09 January 2018

Open Access This article is licensed under a Creative Commons Attribution 4.0 International License, which permits use, sharing, adaptation, distribution and reproduction in any medium or format, as long as you give appropriate credit to the original author(s) and the source, provide a link to the Creative Commons license,
and indicate if changes were made. The images or other third party material in this article are included in the article's Creative Commons license, unless indicated otherwise in a credit line to the material. If material is not included in the article's Creative Commons license and your intended use is not permitted by statutory regulation or exceeds the permitted use, you will need to obtain permission directly from the copyright holder. To view a copy of this license, visit http://creativecommons.org/licenses/by/4.0/.

(c) The Author(s) 2018

\footnotetext{
${ }^{1}$ Department of Chemical and Biomolecular Engineering, University of California, Berkeley, CA 94720, USA. ${ }^{2}$ Climate and Ecosystem Sciences Division, Lawrence Berkeley National Laboratory, Berkeley, CA 94720, USA. ${ }^{3}$ Energy and Resources Group, University of California, Berkeley, CA 94720, USA. Correspondence and requests for materials should be addressed to K.G. (email: kgeorgiou@berkeley.edu) or to M.S.T. (email: mstorn@lbl.gov)
} 